\title{
Impact of Employee Motivation on Employee Performance (A Case Study of Private firms: Multan District, Pakistan)
}

\author{
Muhammad Nadeem ${ }^{1}$, Naveed Ahmad ${ }^{2, *}$, Muhammad Abdullah ${ }^{3}$, Naqvi Hamad ${ }^{4}$ \\ ${ }^{1}$ Faculty of Management Sciences, National University of Modern Languages, Pakistan \\ 2Faculty of Management Sciences, Indus International Institute, D. G. Khan, Pakistan \\ ${ }^{3}$ Faculty of Management Sciences, Air University, Pakistan \\ ${ }^{4}$ Ghazi University, D. G. Khan, Pakistan \\ *E-mail address: naveeddgk2010@gmail.com
}

\begin{abstract}
This article is based on the private firms which working in Multan city, Pakistan. In this article all we studied and analyzed all aspects of the employee motivation importance especially in private firms. In Pakistan many employees who are working in private firm (especially in Multan) facing motivational problem. But many private firms working for the employee motivation and encouraging the employees. In this we also mentioned major factors which can help the firms to achieve employee motivation. We also observed employee motivation is so important for the employee's performance and efficiency and for the private firm's success. A questionnaire was developed for estimating effect of employee motivation on firm's performance. Data was collected through convenience sampling method. Our sampled people include both, managers and non managers of private firms in Multan city. This research study will contribute into existing literature through indicating the importance of employee motivation on performance.
\end{abstract}

Keywords: private firms; Multan; motivational problem; employee motivation

\section{INTRODUCTION}

Each firm desires to achieve success and has need to urge continuous growth. This era is extremely aggressive and firms not with standing volume and promote focus face worker difficulties. To beat the chains robust, optimistic association ought to be formed. Personnel, workers of firm are the foremost middle half in order that they got to be unfair and convinced towards responsibilities completion.

In order to attain their goals and objectives, firms style completely different methods. In reality some firms realize the fact that workers are the major part of the firms and they can get the targets of the firms. If the workers of the firms are not happy, they will not take interest in attaining the targets of the firms and firms will not be able to get their targets. The purpose of this paper is to know the effect of encouraging workers on performance in private firms, particularly in Multan District, Pakistan. 
As compared to the public sector, the employees of the private sector are less motivated in Pakistan. In Pakistan many firms are owned by single person. They have their family owned businesses, for their own interests they cannot focus on the other employee's interests who are working in the firm. First objective of this paper is to know how employees can be encouraged. Second objective is to find the connection between employee motivation and efficiency of the firm.

\section{LITERATURE REVIEW}

\section{1. Motivation}

According to Webster's New lexicon, a motive is "wish to do something". "Motivate suggests that "offer reasonably," motivation is outlined "inspiring method". Motivation is process that associate degree goal which someone to attain. Butkus \& Green (1999) found that motivation suggests that to maneuver, power to carry on for satisfying a wish. Martin and Bartol (2003) discussed that an influence which improves performance and maintain it. This clarification identifies that so as to achieve assured targets; people should be adequately active and be obvious regarding their goals. Bedeian, (2006) found that it's an indoor drives to satisfy associate degree unhappy want and also the wish to achieve. It's the terminal product of interface among temperament behavior and formal distinctiveness (IRCO). Motivation may be a set of courses involved with a child of power that enhances efficiency and leads to achieve goals (Kalimullah, et al, 2010). Barron in 1991 found that it is associate degree accumulation of various routes that direct and precise our actions to achieve some explicit desires.

\section{2. Employee inspiration}

Rizwan et al in (2012) found monetary, cost-effective are the ideas which give firms benefits over other firms comparatively. Manzoor et al, (2012) discussed that worker efficiency essentially rely upon several things such as worker evaluation, worker incentive, worker happiness, worker reward, training and career protection and formal arrangement. Workers are responsible for the targets they should come through. Rutherford (2011) rumored incentive develops associate degree firm a lot of flourishing as a result of angry staff are perpetually yearning for improved practices to try and do a piece, thus it's necessary for corporations to influence their staff inspiration.

\section{3. Employee performance}

Work presentation of each worker shows his attitude towards attaining his objectives. Management of the corporations set targets for the workers on the basis of the efficiency of top level workers. Where as the efficiency of each worker, abilities of each worker are different which results variability in the performance of the workers. Job presentation displays efficiency and potency that create a reimbursement to firmal targets. Within the past staff weren't able to create work connected selections as a result of the system of the firm doesn't allow them to try. Lawler and Hall (1970) discussed through analysis that workers interest and their will to complete their duties are not linked with their performance on the job.

They thought performance of the workers can be improved through links with the community, public etc so the work is not important as the relations. The control concept of Nineteen Seventies is that happy staff are more productive. Work pleasure is important for workers to attain their goals as proved in many theories and cases. worker presentation in the 
main depends upon several things such as worker evaluation, worker incentive, worker happiness, worker reward, training and, career protection, firmal arrangement. However this paper is targeted on solely two most essential factors: coaching and motivation of the worker.

\section{4. Firmal efficiency}

Work of individuals that create freelance company characteristics for a few definite reason is usually called firm and obtaining desired outcome at intervals outlined asset is considered as efficiency. Efficiency of the firm is measured as how efficiently it attains its desired targets through the performance of workers which are set in the corporations (Muhammad, et al, 2011). Firmal effectiveness is outlined because the extent to that associate degree firm, by the utilization of sure resources, attain targets while not depleting its assets. Yuchtman E in (1987) discussed that firms have limited resources and they have to utilize these resources efficiently to take the benefits of these limited resources in the competitive environment.

\section{5. Factors affecting employees' motivation}

Contemplate wage structures that ought to embody importance firm attach to every job, payment in line with presentation (Adeyinka, et al, 2007). Guidance of the workers is also very important and necessary to work with and through other people because workers should have confidence on the management to get the work done efficiently and effectively (Baldoni $\mathrm{J}$, 2005). So many studies and theories proved that workers and managers encourage each other (Rukhmani K, 2010). Inspiration should be from the managers of the firms to encourage the workers to attain the targets (Baldoni J, 2005).

To encourage the workers of the firm empowerment is also used to make the workers happy and to keep their interest in attaining the goals of the firms. Actually it is beneficial for both workers and the corporatons. Empowerment can increase the abilities and efficiency of the workers because they feel happy and take interest in attaining their tasks efficiently (Yazdani B. O., et al, 2011).

Faith is outlined because the perception of some one, call to do something, activities and their call (Hassan et al, 2010). If associate degree firm needs to boost and achieve success, trust plays a major role thus it must always be preserved to make sure associate degree corporations survival and to reinforce worker's inspiration (Annamalai.T,2010). No matter however machine-driven associate degree firm is also, high productivity depends on the extent of motivation and also the effectiveness of the manpower thus employees coaching is associate degree indispensible strategy for motivating employees, a method managers will instigate motivation is to convey applicable information of their proceedings (Adeyinka, et al, 2007).

\section{6. Motivation result on worker productivity}

Motivated staff are inclined to be a lot of productive than non-motivated staff. Most businesses create some pains to encourage employees however this can be usually easier aforesaid than done. Staff are all people with completely different like's dislikes and wishes, and various things can encourage every. Productivity is that which individuals will turn out with the tiniest quantity effort Productivity may be a quantitative relation to calculate however well associate degree firm into product and services.

1. Actuated staff is a lot of Productive 
If worker are happy and happy then he/she can do his /her add a awfully spectacular approach, then the result are smart, on the different opposite hand actuated worker can encourage other staff in workplace.

2. Decision-making and sensible Expectations

It is necessary to interact staff within the decision making deciding higher cognitive method process.

3. Description, Work setting and suppleness

workers doing right thing at the right time under the guidance of the supervisor will also increase the motivation and satisfaction of the workers. Flexible working hours, home assignments, discussion with the workers also increase the level of motivaion of the workers.

4. Pay and advantages

Keeping staff actuated with smart advantages is simple. Corporations also give good salary packages and different advantages to their workers to improve their efficiency.

\section{RESEARCH METHODOLOGY}

\section{1. Research Design}

The design that used for this study is that the descriptive technique. A descriptive analysis could be an assortment and interpretation of information. Information collected by asking a greater number of people from the sample chosen with known backgrounds. This research is conducted with individuals from completely separate areas. The questionnaires were conducted to seventy five employees who are operating in numerous departments with completely different work tasks and firm place.

A sample size of fifty three was calculated through convenience sampling methodology. Convenience sampling could be a straightforward approach wherever a sample is chosen consistent with the convenience of the research worker. This convenience is also in respect of convenience of knowledge, accessibility of the Scale Validity and dependability.

\section{2. Techniques for Data Collection}

The procedures for collection of data for this study were basically questionnaires and observation. Only one type of questionnaire was given to both junior and senior employees and management to answer. These questionnaires were made up of 17 questions of which most of the questions were close-ended. Observation is critically studying the behaviors of employees in the working environment when they have been motivated. That is the behaviors they put up either positive or negative and the effects, it can have on their performance in the firm.

\section{SUMMARY/CONCLUSION OF THE QUESTIONNAIRE}

After conducting and analyzing the questionnaire, author observed the importance of motivation. How much employee motivation is necessary for firm performance/productivity as well as for the employee performance? Some results related to the questionnaire are given below: 
- For what number of years you're worked with this firm
Less than one year
$(9.5 \%)$
$1-3$ years
$(26.7 \%)$
3-5 years
$(21.5 \%)$
$5-10$ years
$(38.4 \%)$

The analysis was directed to search out information on the length of service the worker has been with the firm. Survey results indicated that highest $38.4 \%$ respondents had been operating between 5-10 years and this followed by respondents $26.7 \%$ who are with the firm between 1- three years. Respondents who are operating for the shortest amount of your time but one year stood with respondents seven $9.5 \%$.

- What is your job responsibility?

$\begin{array}{ll}\text { Operative worker } & (60.50 \%) \\ \text { Supervisor } & (28.28 \%) \\ \text { Manager } & (6.6 \%) \\ \text { Senior Management } & (4.9 \%)\end{array}$

The analysis inquired to search out the character of jobs of respondents. The analysis showed that highest respondents $60.50 \%$ were engaged in operative worker connected job responsibilities and this closely followed by respondents $28.28 \%$. These were followed next by Manager that is $(6.6 \%) \&$ Senior Management that's $(4.9 \%)$.

- How much happy you're in this firm?

$\begin{array}{ll}\text { Very happy } & (14.5 \%) \\ \text { Satisfied } & (58.5 \%) \\ \text { Neutral } & (21.2 \%) \\ \text { Dissatisfied } & (5.7 \%) \\ \text { Very dissatisfied } & (1.9 \%)\end{array}$

The analysis was directed to search out however happy the respondents square measure with their gift firm and results shows that terribly happy (14.5\%), Satisfied $(58.5 \%)$ Neutral (21.2 \%), Dissatisfied (5.7\%) terribly Dissatisfied (1.9\%)

- Supervisor Listens to staff

Positive Agreement: $\quad(71.02 \%)$

Neutral:

Disagreed:

$(3.77 \%)$

Supervisors have information regarding employee's work

Positive Agreement: $\quad(65.25 \%)$

Neutral: $\quad(29.09 \%)$

Supervisor being truthfulness to staff

Positive Agreement: $\quad(58.04 \%)$

Neutral:

$(30.19 \%)$

Disagreed:

$(11.77 \%)$

Supervisor Support personal development

Positive Agreement: $\quad(61.70 \%)$

Neutral: $\quad(34.53 \%)$ 
Disagreed:

$(1.89 \%)$

Supervisor has realistic expectation of worker contribution

Positive Agreement: $\quad(63.92 \%)$

Neutral:

$(24.53 \%)$

Disagreed:

$(11.55 \%)$

Supervisor being truthful to staff

Positive Agreement: $\quad(57.0 \%)$

Neutral:

$(39.19 \%)$

Disagreed:

$(3.77 \%)$

Relationship you're with boss

Very Good: $\quad(27.63 \%)$

Good: $\quad(48.15 \%)$

Neutral: $\quad(22.37 \%)$

Boss's / Supervisor's management skills

Very Good: $\quad(22.37 \%)$

Good: $\quad(45.15 \%)$

Neutral: $\quad(25.78 \%)$

Bad: $\quad(4.89 \%)$

Very Bad (11.9\%)

Communication with general management

Very Good: $\quad(24.37 \%)$

Good: $\quad(22.07 \%)$

Neutral: $\quad(40.44 \%)$

Bad: $\quad(11.26 \%)$

Very bad (10.8\%)

Appreciation from management

Very Good: $\quad(13.26 \%)$

Good: $\quad(36.33 \%)$

Neutral $\quad(36.74 \%)$

Bad: $\quad(11.81 \%)$

Very Bad (12.67\%)

Career development support from supervisor/management

Very Good: $\quad(11.36 \%)$

Good: $\quad(37.64 \%)$

Neutral: $\quad(42.56 \%)$

Bad: $\quad(9.74 \%)$

Very Bad $\quad(7.06 \%)$

Mark your satisfaction level together with your supervisor manager or management for response to suggestions projected by you?

Very happy 8

Satisfied $\quad 31$

Neutral 5

Dissatisfied 6

Very dissatisfied 3

Investigation on the satisfaction levels of staff to suggestions they propose to supervisor, manager and therefore the management indicated that satisfaction registered with thirty one respondents $59.6 \%$ 


\section{1. Limitation of the study}

This research study has following limitations:

- Only private firms are considered to check the impact of motivation on performance.

- The length of the questionnaire - around seventeen queries.

- Another limitation of the study which faced during the research article is difficulty to access the company's internal information.

- This study is conducted only in the private firms of Multan district of Pakistan.

\section{CONCLUSION AND FUTURE DIRECTION}

The literature and varied studies finished that factors: direction, recognition, incentives and different psychological feature factors have positive impact on worker motivation, additionally there is an encouraging association between worker inspiration and firmal efficiency. Those workers who are working in the private firm need more motivation as compared to the public firms.

According to the research study employee motivation is necessary for all the firms. It does create a great impact on the firm and employee performance. Increase their efficiency and effectiveness and helps in the achievement of the firm target. It is observed that the firms which take cares of their workers progress rapidly. This research investigated two factors, authorization and worker identification and different factors for attractive worker inspiration that ends up in firmal effectiveness. In future this text particularly the two psychological feature factors: worker authorization and worker recognition can play vital role within the succession of the personal firm.

\section{References}

[1] Annamalai T., Abdullah A. G. K., Alasidiyeen N. J., European Journal of Social Sciences 13(4) (2010) 623-632.

[2] Aydeninka B., Ceylan A., Development and Learning in Organizations 23(3) (2007) 21-23.

[3] Baldoni J., (2005). Motivation Secrets. Great Motivation Secrets of Great Leaders WWW page. URL http://govleaders.org/motivation_secrets.htm

[4] Baron R. A., Motivation and Emotion 15(1) (1991) 1-8.

[5] Bedeian A. G., Hunt J. G., The Leadership Quarterly 17(2) (2006) 190-205.

[6] Butkus R. T., Green T. B. (1999). Motivation, Beliefs, and Organizational Transformation. ABC-CLIO.

[7] Hassan R. A., Fuwad B. A., Rauf A. I., Academy of Strategic Management Journal 9(2) (2010) 123-131.

[8] Kalimullah A. R., Yaghoubi N. M., Moloudi J., European Journal of Economics, Finance and Administrative Sciences 24 (2010) 165-171.

[9] Lawler E. E., Hall D. T., Journal of Applied psychology 54(4) (1970) 305. 
[10] Manzoor Q. A., Business Management and Strategy 3(1) (2012) 1.

[11] Martin D. C., Bartol K. M., Journal of International management 9(2) (2003) 115-132.

[12] Muhammad M. E., Ghafoor M. M., Naseer S., Far East Journal of Psychology and Business 2(1) (2011) 37-48.

[13] Rizwan S. U., Cornell L. Rev. 98 (2012) 493.

[14] Rukhmani K., Ramesh M., Jayakrishnan J., European Journal of Social Sciences 15(3) (2010) 365-369.

[15] Rutherford H. J., Lindell A. K., Emotion Review 3(3) (2011) 333-343.

[16] Yazdani B. O., Yaghoubi N. M., Giri E. S., European Journal of Social Sciences 20(2) (2011) 267-274.

[17] Yuchtman E., Seashore S. E., American Sociological Review 32 (1987) 891-903.

[18] Nadeem Iqbal, Naveed Ahmad, Zeeshan Haider, Sonia Anwar, International Letters of Social and Humanistic Sciences 5 (2014) 73-80.

[19] Nadeem Iqbal, Naveed Ahmad, Komal Javaid, International Letters of Social and Humanistic Sciences 6 (2014) 60-73.

[20] Nadeem Iqbal, Naveed Ahmad, Maira Abrar, Aisha Hassan, International Letters of Social and Humanistic Sciences 7 (2014) 31-43.

[21] Nadeem Iqbal, Naveed Ahmad, Zeeshan Riaz, International Letters of Social and Humanistic Sciences 9 (2014) 14-25.

[22] Nadeem Iqbal, Naveed Ahmad, Hafeez Ullah, Aun Abbas, International Letters of Social and Humanistic Sciences 24 (2014) 15-25. 